\title{
A CASE OF SPORADIC CONGENITAL GOITRE
}

BY

\author{
A. L. D'ABREU and B. S. B. WOOD
}

From the Children's Hospital, Birmingham

(Received for Publication October 31, 1949)

Since the general use of iodine prophylactically in endemic goitre areas gross enlargement of the thyroid gland at birth has become relatively uncommon. Wegelin's (1926) series in the preiodine period of 223 consecutive necropsies on newborn infants in a goitre area between 1911 and 1921 showed that $34 \%$ had thyroid glands weighing over $6 \mathrm{~g}$. The normal weight of the gland at birth in a healthy infant is 1.5 to $2 \mathrm{~g}$.

The following case is apparently one of sporadic congenital goitre without any evidence of thyroid dysfunction or goitre in the mother or her family. Surgical intervention afforded an interesting opportunity to examine histologically the thyroid gland at two different stages after treatment with thyroid extract.

\section{Case Report}

R.B., a boy and the first child, was born on September 10, 1948. His birth weight was $7 \mathrm{lb} .7 \mathrm{oz}$

The mother's history revealed no evidence of goitre, hypothyroidism, or dietary deficiency, and no possible goitrogenic drug had been taken. She had never lived in an area regarded as goitrous and the family history was free of thyroid disease.

The baby was born at term but delivery by forceps was necessary on account of a prolonged second stage labour, possibly due to poor foetal head flexion. At birth the neck was noted to be grossly swollen causing extreme head retraction, and stridor developed a few days later together with difficulty and cyanosis during feeds. The infant was admitted to Worcester Royal Infirmary when 10 days old and transferred the following day to the Birmingham Children's Hospital.

The appearance of the infant was arresting (Fig. 1). The face was congested and the head hyper-extended because of a large, soft, bi-lobed swelling with a well developed isthmus high up in the neck which obscured all the normal anatomical structures. The swelling had the configuration of a grossly enlarged thyroid gland, but the consistency of a cystic hygroma; it was quite symmetrical, was not transilluminable, and moved on deglutition. No bruit was audible.

A lateral radiograph of the neck demonstrated a large soft-tissue mass in the neck which was displacing the pharynx, larynx, and upper part of the oesophagus forwards and causing considerable angulation (Fig. 2).

The blood cholesterol level was $160 \mathrm{mg}$. \%.

Treatment. Treatment with thyroid extract and iodine was started at once; thyroid (gr. 1 ) and Lugol's iodine (minims 2) were given daily from the thirteenth to the twenty-seventh day of life. No improvement of the dyspnoea or stridor followed and surgical relief became imperative.

The first operation was performed on October 9, 1948, (A.L. d'A.). Owing to distortion of the larynx and trachea a tracheal tube could not be passed. Through a collar incision the left lobe of the thyroid gland was

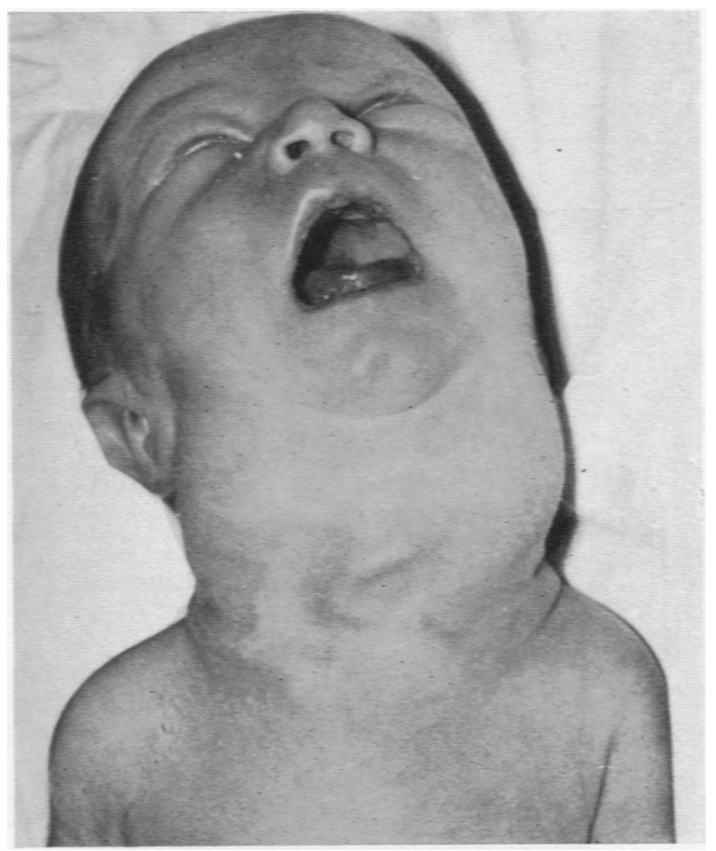

FIG. 1.-Condition on admission. 


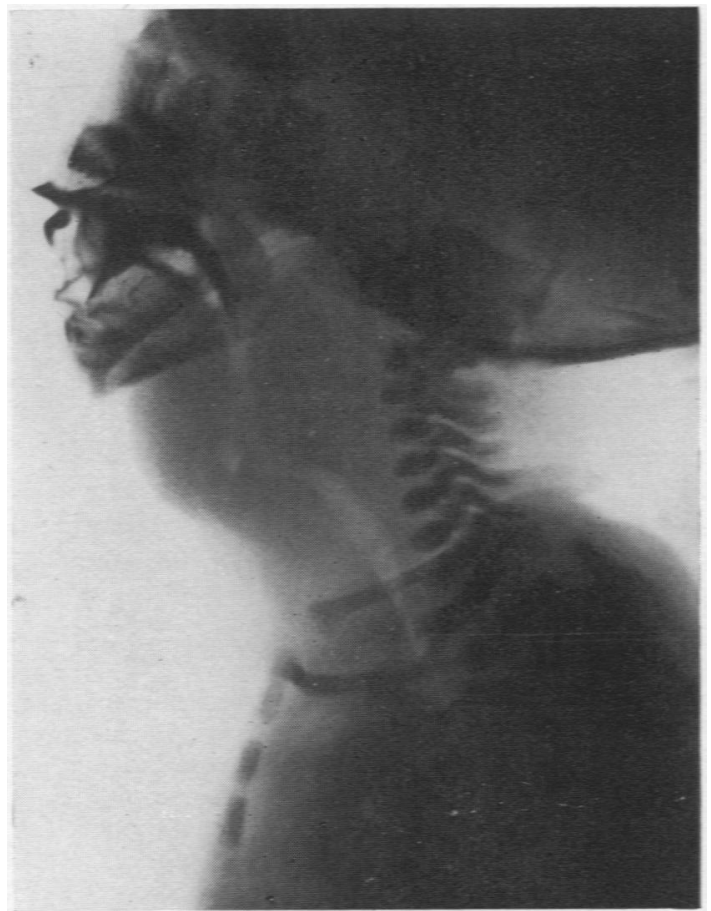

Fig. 2.-Lateral radiograph of the neck on admission.

exposed and found to be very large with a retrolaryngeal portion and a retrosternal prolongation. Five-sixths of this lobe was resected. The parenchyma of the gland was not very vascular but the superior and inferior thyroid arteries were large and were ligated away from the gland. Only one lobe was dealt with because:

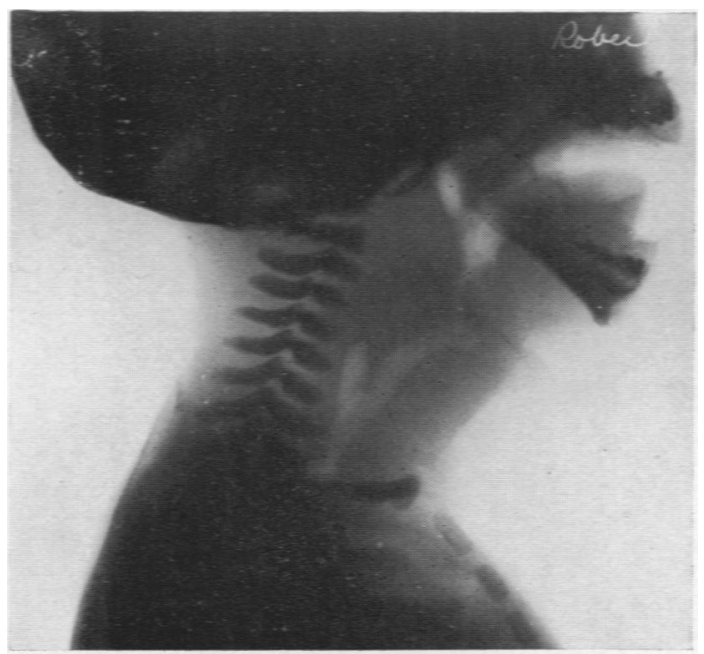

FIG. 3.-Radiograph taken six days after first operation.
(1) The retrolaryngeal and retrosternal portions were considered to be the cause of the respiratory obstruction and their removal would overcome the associated pressure symptoms. (2) Hemithyroidectomy as an emergency operation was considered to be as much as could safely be undertaken in an infant of this age. (3) If relief was inadequate further thyroid tissue could be removed later.

The respiratory obstruction was immediately relieved, but within a few days the stridor and the feeding difficulty returned, though to a less extent than previously. The radiograph (Fig. 3) taken at that time shows less angulation and less forward displacement of the larynx and trachea. Accordingly thyroid extract, this time in the larger dose of gr. $\frac{1}{2}$ daily, was administered from the tenth post-operative day, and was increased on the twenty-first post-operative day to $\frac{3}{4}$ gr. per day. During the next fortnight the neck swelling decreased in size, but the baby began to show signs of mild hyperthyroidism with restlessness, tachycardia, and a voracious appetite, and was taking nearly 70 calories per pound per day of a milk mixture. The thyroid extract dosage

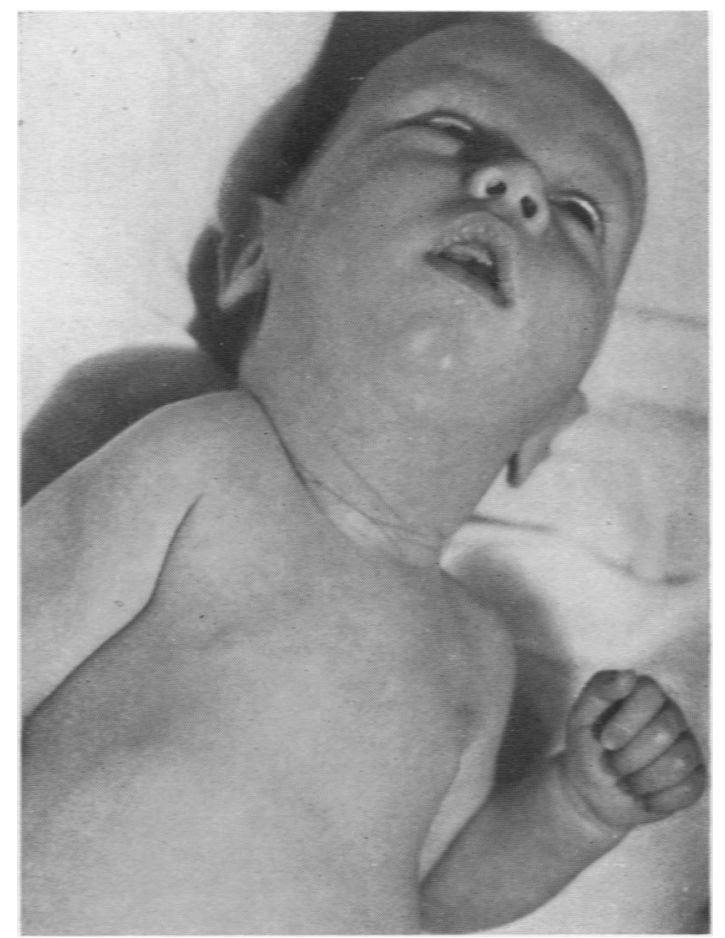

Fig. 4.-Two weeks after second operation.

was therefore reduced to $\frac{1}{2}$ gr. daily seven weeks after operation. The blood cholesterol level at this time was $130 \mathrm{mg} .{ }^{\circ}$. A week later the infant, now three months old and weighing $10 \mathrm{lb}$., was still having difficulty with feeding which caused attacks of cyanosis and stridor. 


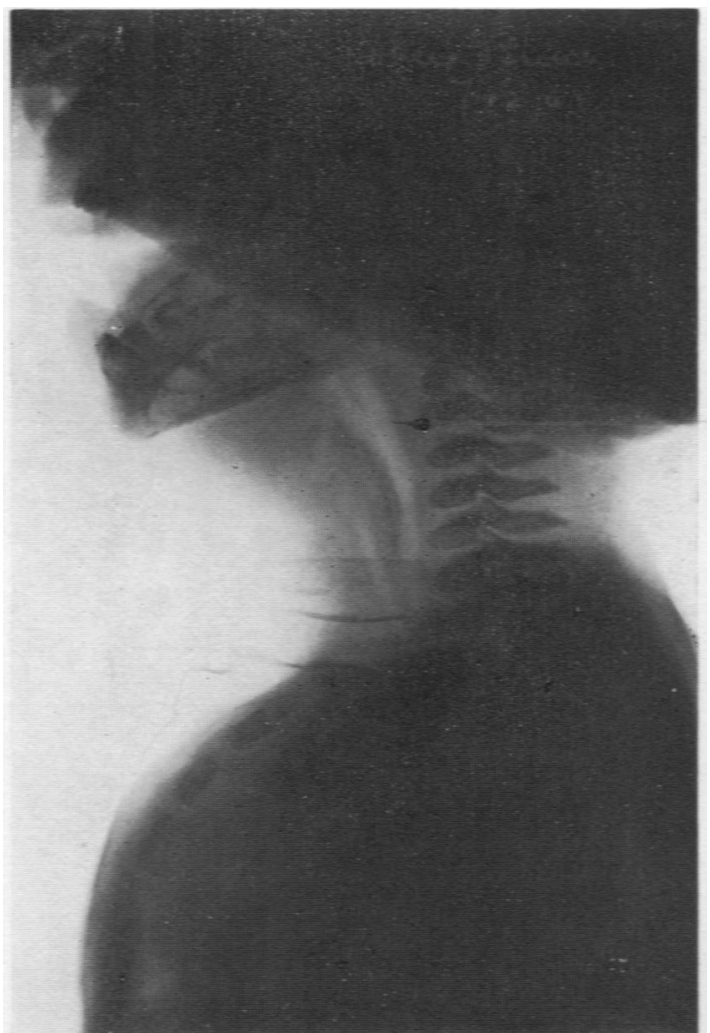

Fig. 5.-Radiograph taken five days after second operation.

The head retraction was as marked as ever. A stage of uneasy equilibrium had now been reached when it was considered that any added burden such as a respiratory infection would probably have proved fatal. For this reason it was considered necessary to undertake further surgical treatment.

The second operation was performed on December 2 , 1948 (A.L. d A.). The right lobe was exposed and found to be much firmer than that previously removed. Retrolaryngeal and retrosternal portions were again present and were removed together with five-sixths of the remaining lobe. The gland was remarkably avascular although the inferior thyroid artery was very large. The post-operative course was uneventful and subsequent progress satisfactory. No further thyroid extract was given. The blood cholesterol level dropped to $114 \mathrm{mg} .{ }^{\circ}$. Fig. 4 shows the appearance of the baby 14 days after the second operation, and Fig. 5 is the lateral radiograph taken at the same time. All neck swelling has disappeared and the position of the pharynx, larynx, and trachea is now normal. When the infant was last seen at the age of 11 months he weighed $19 \mathrm{lb} .10 \mathrm{oz}$. and there were no evidences of hypothyroidism except that on exertion a little stridor could be elicited (Fig. 6).

\section{Pathological Reports}

The first specimen was obtained after thyroid extract gr. $\frac{1}{4}$ and Lugol's iodine minims 2 had been given for 14 days, and the second after 44 days of treatment with thyroid $\frac{1}{2}$ or $\frac{3}{4}$ gr. a day to the limit of tolerance. Dr. Baar reported on the specimens as follows:

The first specimen removed on October 9, 1948, consisting of the left lobe of the thyroid gland and part of isthmus, measured $4 \times 3 \times 2.5 \mathrm{~cm}$., and was well encapsulated. The cut surface was smooth and yellowish grey in colour with narrow strands of white tissue. The vesicles are lined by columnar, or occasionally cubical, epithelium with a cell height of 17.5 to $25 \%$. One or two papilliform proliferations of the epithelium can be seen. The lumina are very small and mostly empty of colloid which when present takes stain poorly. The stroma is scanty and not hyperaemic, the strands being 12.5 to $150 \mu$ (Fig. 7).

The second specimen, removed on December 2, 1948, consisting of the right lobe of the thyroid, measured $4.5 \times 3 \times 2.2 \mathrm{c}$. and weighed $14.8 \mathrm{~g}$. No vesicular structure was seen macroscopically.

Vesicles are larger than in the previous specimen, the diameter being 15 to $50 \mu$, and the cell height is 6.25 to $7 \cdot 25 \mu$. More of the vesicles contain colloid which is

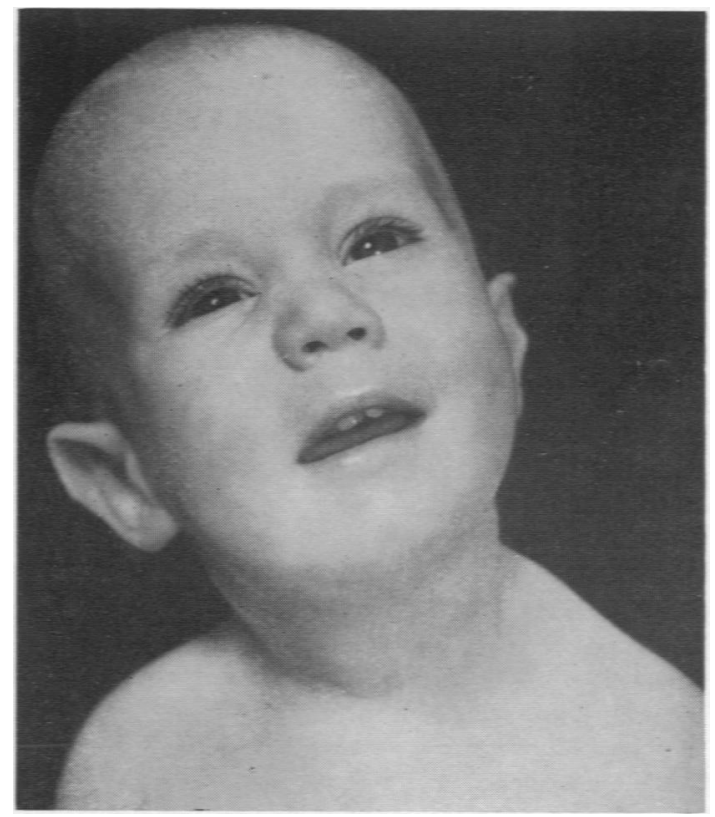

FIG. 6.-Child aged one year.

still pale and often granular. The stroma is more abundant and the strands vary from 25 to $500 \mu$ in width. The histological picture is that of hyperplastic thyroid tissue with evidence of incipient involution (Fig. 8). 


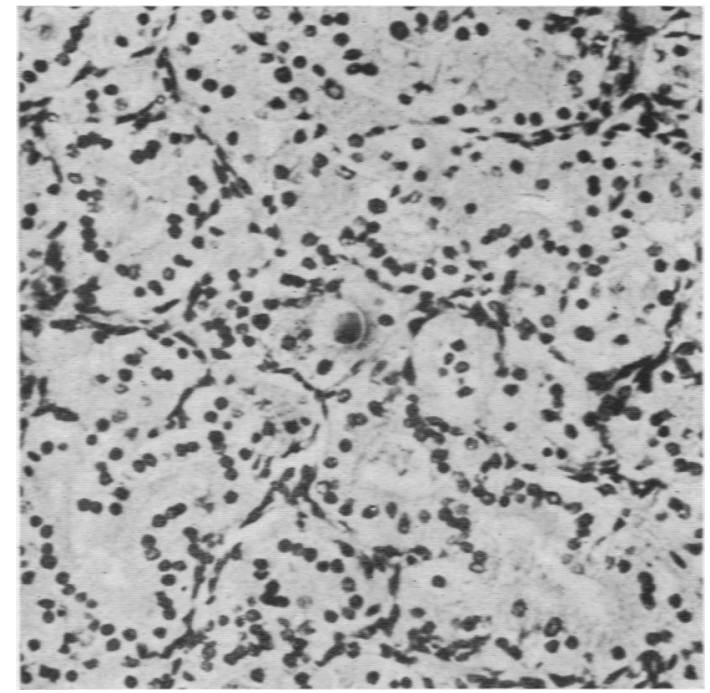

Fig. 7.-Section of thyroid gland removed after 14 days' treatment.

\section{Discussion}

The cause of the enlargement of the thyroid in this infant is difficult to explain. It has been shown by Skinner (1924 and 1928) that a deficient iodine intake by a woman during pregnancy is an important factor in the production of thyroid enlargement in infants at birth, but there is no evidence to suggest any such deficiency in our case. Hypothyroidism or maternal goitre are other causes that have been advanced (Neurath, 1925; Hill, 1933; Davies, 1943); and Solis-Cohen, and Steinbach (1939) postulate that iodine deficiency may cause simple goitre in one generation, hypothyroidism in the second, and congenital goitre or cretinism in the third generation.

Maternal Graves' disease causing enlargement of the thyroid in the newborn infant must be an uncommon occurrence in view of the rarity of pregnancy going to term in such cases. Recently, however, an infant with a moderately enlarged goitre at birth was admitted to the Birmingham Children's Hospital and the mother was found to have definite signs of hyperthyroidism with enlargement of the gland.

The cases reported by Parmelee, Allen, Stein, and Buxbaum (1940), Rienhoff (1940), and Kunstadter (1948) are apparently similar to ours in that they were sporadic and of unexplained aetiology.

In our case there was nothing to suggest thyroid disturbance of the mother either in her history or when seen after delivery, but it is possible that there might have been a latent or temporary hypothyroidism during pregnancy owing to increased demands during this time. Many substances such as cabbage, cyanide, sulphaguanadine and, of course, thiouracil, are known to cause temporary thyroid insufficiency. Although this infant's mother admitted to taking aspirin and also received a short course of sulphonamide therapy during pregnancy, the necessity for these drugs is too frequent an occurrence in this country to be considered seriously. In this connexion, however, Astwood's (1949) recent work with radioactive iodine for detecting antithyroid substances may have considerable significance.

Although Bartels (1941) believes that congenital goitre and endemic cretinism are not inherited, the importance of heredity in some forms of thyroid disease has been emphasized by Jackson (1949), especially in goitre-free areas.

The clinical features in our case were very similar to those described by Wieland (1927) who makes a particular note of the neck extension, the stridor

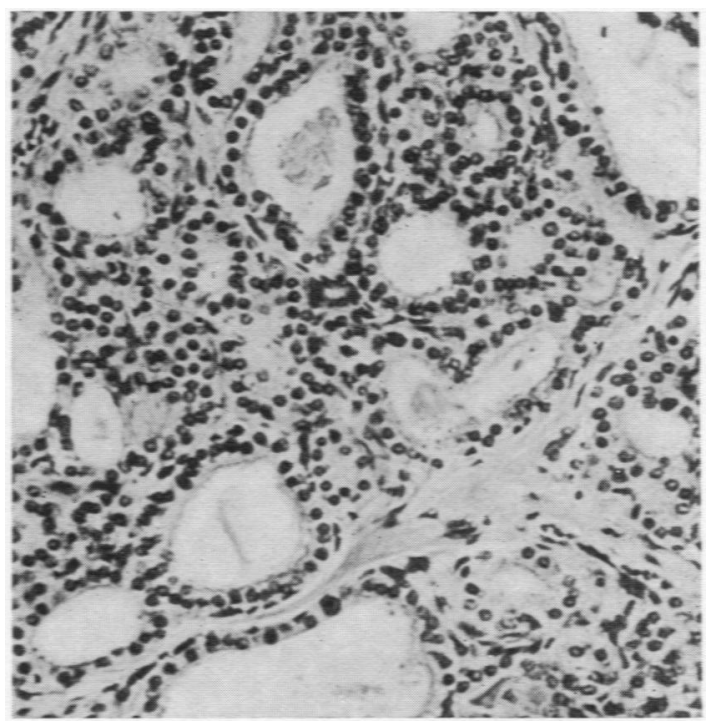

FIG. 8. - Section of thyroid gland removed after 44 days' treatment.

which largely disappears during sleep or on relaxation, the low hoarse cry, and the accentuation of all these symptoms by feeding. Although he states that the prognosis is good if the infants survive after 24 to 36 hours, the literature already quoted concerning the larger glands provides a gloomier picture.

In view of the experience of Plummer and Boothby (1924), Rienhoff (1940), and Smallpeice (1949) we first tried medical treatment with both iodine and 
thyroid extract, and from the histological pictures at the different stages of medication with thyroid extract it is apparent that there was a significant regression in the activity of the gland, which tends to confirm the clinical impression of a reduction in size of the neck swelling.

On reflection larger doses (gr. $\frac{1}{2}$ to $\frac{3}{4}$ a day) of thyroid extract from the beginning of treatment might have been more beneficial, but it is most improbable that removal of part of the gland could have been avoided in this particular case.

As regards surgical treatment, tracheotomy is apparently dangerous owing to the risk of subsequent bronchopneumonia at this age. Isthmectomy has been advised but would have been unsuccessful in this case because of the retrolaryngeal and retrosternal portions. The general opinion is that hemithyroidectomy is the operation of choice if surgery becomes necessary. Cretinism may develop even without surgical interference (Hurxthal and Musulin, 1946) and this child will have to be watched carefully, but so far he has not shown any clinical evidence of thyroid insufficiency.

\section{Summary}

A case of sporadic congenital goitre causing severe respiratory embarrassment is described.

Despite intensive treatment with both thyroid extract and iodine surgical relief became necessary.

The histological findings in the thyroid giand at different stages of oral thyroid administration are described.

The literature is briefly reviewed and the management of such cases is discussed.

We wish to thank Professor J. M. Smellie for permission to report this case. We are also indebted to Dr. A. G. V. Aldridge, who referred the infant to us, to Dr. Baar for the histological reports, and to Mr. G. Williamson for the photographs.

\section{REFERENCES}

Astwood, E. B. (1949). Ann. intern. Med., 30, 1087. Bartels, E. D. (1941). 'Heredity in Graves's Disease.' Copenhagen.

Davies, J. R. (1943). J. Pediat., 22, 570.

Hill, A. L. (1933). Arch. Pediat., 50, 424.

Hurxthal, L. M., and Musulin, N. (1946). Amer. J. Med., 1, 56.

Jackson, W. P. U. (1949). Lancet, 2, 198.

Kunstadter, R. H. (1948). J. Pediat., 32, 711.

Neurath, R. (1925). Wien. klin. Wschr., 38, 1206.

Parmelee, A. H., Allen, E., Stein, I. F., and Buxbaum, H. (1940). Amer. J. Obstet. Gynec., 40, 145.

Plummer, H. S., and Boothby, W. M. (1924). J. Amer. med. Ass.,, 83, 1333.

Rienhoff, W. F. Jnr. (1940). Arch. Surg., Chicago, 41, 487.

Skinner, H. H. (1924). J. Amer. med. Ass., 82, 1190. (1928). M. J. and Rec., 127, 381.

Smallpeice, V. (1949). Lancet, 1, 565.

Solis-Cohen, L., and Steinbach, M. (1939). Amer. J. Dis. Child., 58, 1067.

Wegelin, C. (1926). In Henke-Lubarsch, ' Handbuch der Speziellen Pathologischen Anatomie und Histologie,' Vol. 8. Berlin.

Wieland, E. (1927). Schweiz. med. Wschr., 57, 850. 